\title{
Treating pediatric plaque psoriasis: challenges and solutions
}

This article was published in the following Dove Press journal:

Pediatric Health, Medicine and Therapeutics

2I April 2016

Number of times this article has been viewed

\section{Jayakar Thomas'}

Kumar Parimalam²

'Department of Dermatology, Sree Balaji Medical College, Bharath University, Chennai, Tamil Nadu, India; ${ }^{2}$ Department of Dermatology, Villupuram Medical College, Villupuram, Tamil Nadu, India

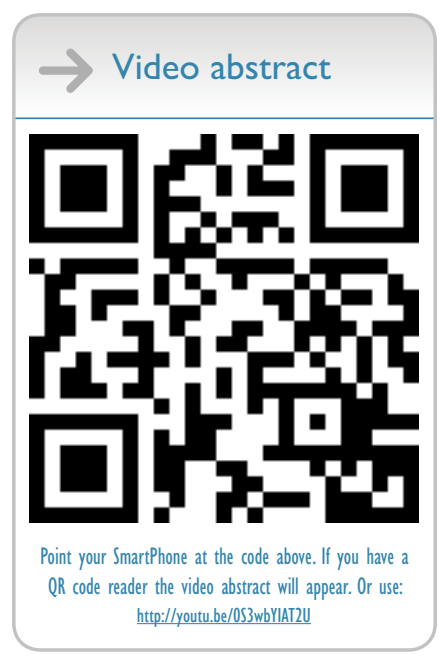

Correspondence: Jayakar Thomas Department of Dermatology, Sree Balaji Medical and Bharath University, 7 Works Road, Chromepet, Chennai 600044, Tamil Nadu, India Email jayakarthomas@gmail.com

\begin{abstract}
Psoriasis is a T-lymphocyte-mediated chronic inflammatory disorder involving the skin and joints. Nearly $3.5 \%$ of the population has been diagnosed to have psoriasis. In a dermatology department, almost one-third of psoriasis patients are in the pediatric age group. With an annual prevalence of up to $0.71 \%$, childhood psoriasis can now be regarded as a frequently seen chronic inflammatory skin disorder having a significant impact on the quality of life. Based on the age of onset, psoriasis in children can be broadly classified as infantile psoriasis that can be mostly self-limited, psoriasis having an early onset, which needs specific treatment, and psoriasis that is associated with arthritis. Treating a child with psoriasis is a challenge, considering the physical development, body metabolism, rate of cutaneous absorption, and metabolism of drugs, which are quite different from those of the adults. The long duration of sun exposure for the rest of their life makes it more demanding while considering phototherapy in children. Long-term treatment of psoriasis, with phototherapy or drugs, needs critical evaluation in children. Hence, a thorough understanding of the disease in all its aspects will certainly help manage childhood psoriasis better. Timely diagnosis and adequate management not only arrest progression but also minimize the psychological burden caused by the disease, averting disfiguring states and evolution into a metabolic syndrome.
\end{abstract}

Keywords: plaque, psoriasis, children, treatment

\section{Epidemiology}

Nearly one-third of adult patients with psoriasis have had a history of the disease in childhood. Incidence of pediatric psoriasis varies between different ethnic groups, being highest in Caucasians and Blacks. ${ }^{1}$ It was recorded that nearly 40,000 children under the age of 10 years have psoriasis in the UK. ${ }^{2}$ The prevalence of psoriasis in younger children is apparently more because of the increased incidence of diaper rash and its inclusion as psoriatic rash. Though the exact age of onset is not clear, first sign of the disease occurs before the age of 18 years. ${ }^{3}$ The distribution of psoriasis is almost equal in boys and girls. It is of interest to note that in the age group $<20$ years, psoriasis was seen more in girls than in boys. ${ }^{4}$ Family history of psoriasis was more frequently elicited in pediatric onset psoriasis (POP) when compared to adult onset psoriasis (AOP). ${ }^{5}$ Familial incidence was reported in as high as $89 \%$ of children with psoriasis. ${ }^{6}$ Regarding the clinical type of psoriasis, it was found that nearly two-third of children present with plaque-type psoriasis. ${ }^{7}$ Though joint involvement in children with psoriasis less than $1 \%,{ }^{8}$ it should be looked for in children with severe plaque-type psoriasis. Genetic background and a positive family history have been documented in more than half of the children with psoriatic arthropathy. ${ }^{9}$ submit your manuscript Dovepress
Pediatric Health, Medicine and Therapeutics 2016:7 25-38

(c) (i) (5) 2016 Thomas and Parimalam. This work is published and licensed by Dove Medical Press Limited. The full terms of this license are available at https://www.dovepress. cc) ${ }_{\mathrm{BY}} \mathrm{NC}$ com/terms.php and incorporate the Creative Commons Attribution - Non Commercial (unported, v3.0) License (http:///creativecommons.org/licenses/by-nc/3.0). By accessing the work you hereby accept the Terms. Non-commercial uses of the work are permitted without any further permission from Dove Medical Press Limited, provided the work is properly attributed. For permission for commercial use of this work, please see paragraphs 4.2 and 5 of our Terms (https://www.dovepress.com/terms.php). 


\section{Etiopathogenesis}

No single factor is solely responsible for the genesis of the disease. However, genetics seems to play an important role in the etiology of psoriasis, as nearly $90 \%$ of children have a positive family history, ${ }^{6}$ and the disease is more common in identical than in fraternal twins. Genetic studies show that $H L A C w 6$ is the major susceptibility gene in psoriasis. ${ }^{10}$ Major gene for psoriasis susceptibility is found to be located on the sixth chromosome, the site of human leukocyte antigen (HLA) class I. Different antigens are found to be responsible for the difference in age of onset and producing different subtypes of the disease. The specific markers found to be associated with psoriasis were CW6, B13, and B17 with early onset and CW2, CW5, B27, and B44 with late onset disease, respectively. Similarly, it was found that those with $\mathrm{Cw0602}$ alleles are more likely to develop the guttate form of psoriasis. It is known that genetic mutations are associated with developing psoriasis, and a series of such gene mutations have been isolated. ${ }^{11,12}$ Many linkage studies have detected psoriasis susceptibility loci (PSORS), and the study is an ongoing process where so far nine loci (PSORS1-9) have been studied in detail. ${ }^{13}$ It was found that $H L A-C w 6$ allele is strongly associated with early onset psoriasis. ${ }^{14}$ It is observed that precipitating factors are more important in childhood than adult stress. Guttate psoriasis that is precipitated by streptococcal infection can be provoked by pharyngitis and perianal dermatitis of streptococcal origin. Of the viral infections, human immunodeficiency virus (HIV) can induce or exacerbate psoriasis. ${ }^{15}$ Obesity, which is considered a risk factor for psoriasis, can increase the severity of the disease. ${ }^{16,17}$

There is a strong correlation between psoriasis and autoimmune disease and atopy. Coexistence of psoriasis with any of the above has been reported. Expression of the disease clinically depends on the capacity of the child's epidermis to express the same. This is a complex process, involving the cellular and noncellular components and their interaction. Epidermal and dermal cells, cells of the immune system along with the noncellular components of the humoral system, and their interaction lead to the variable expression of the disease. The expression of genetically controlled hyperproliferation and altered differentiation of the keratinocyte depend much on the inherent phenotype. A genetic aberration can therefore trigger the cascade of inflammatory events in the evolution of the disease.

The exact pathogenesis of guttate psoriasis is not elucidated as yet. However, it is postulated that streptococcal infection can trigger an immune reaction in a genetically susceptible host, resulting in manifestation of guttate-type psoriasis. As mentioned earlier, children who are positive for HLA Cw0602 are more prone to develop guttate psoriasis. The observation of streptococcal products and components crossreacting with normal human epidermis leads to the possibility of an autoimmune phenomenon. The degranulation of mast cells, a constant feature found in the early lesions of guttate psoriasis, may have an important role in the disease. It was also recorded that there is an impaired migration of Langerhans cells during an acute episode of guttate psoriasis. ${ }^{18}$

\section{Pathology}

Histopathological findings of psoriasis keep changing from time to time during the evolution of the lesion, and therefore psoriasis can be considered a dynamic disease from the histological point of view. Skin biopsy is performed in children with psoriasis only in case of doubt or for academic purpose, as the diagnosis is predominantly clinical. Therefore, histological study of psoriasis is reserved for confirmation of diagnosis during diagnostic uncertainty or for treatment evaluation.

Hyperkeratosis, parakeratosis, Munro's microabscess, spongiform pustule of Kogoj, diminished or absent granular layer, regular acanthosis, papillomatosis, tortuosity and dilatation of papillary capillaries, and chronic inflammation in the upper dermis are the common features seen in psoriasis. However, Munro's microabscess and Kogoj's micropustules are only histological clues that are not seen in all stages and all cases of psoriasis. All other features can be found in various types of eczemas and other dermatoses. Depending on type, site, and stage of the disease, histological features tend to differ. Leclerc-Mercier et a ${ }^{19}$ have studied various histological patterns in infantile erythroderma and classified them into psoriasiform, spongiform, and ichthyosiform patterns. Psoriasis is now recognized as an immune-mediated inflammatory disease with a predictable genetic predilection. Increased cell signaling through cytokines is the primary immune defect of psoriasis that causes keratinocyte hyperproliferation by upregulating gene expression. T-lymphocytes along with the chemokines and cytokines are responsible for the development and persistence of lesion. Keratinocytes, endothelial cells, dendritic cells, and neutrophils also play an important role in the pathogenesis. The role of transcription factors in the evolution of psoriasis has now been well documented, and understanding of pathogenesis will help in the proper treatment of this chronic relapsing disease by adequately targeting the specific transcription factors..$^{20-22}$

Psoriasis and atopic dermatitis (AD) were once believed to be mutually exclusive. Recently, the two diseases are 
shown not to be mutually exclusive and may coexist in the same individual. ${ }^{23}$ Distinct populations of T-cells are defined by their unique pattern of cytokine production. ${ }^{24}$ Keratinocytes of patients with psoriasis and AD show an intrinsically abnormal and different chemokine production profile. ${ }^{25}$ Despite these differences, both psoriasis and AD share features such as epidermal hyperplasia, aberrant immunity, and skin barrier abnormality. The epidermal differentiation complex has been implicated in both $\mathrm{AD}$ and psoriasis. ${ }^{26}$ The histological finding of both diseases occurring simultaneously even in infancy definitely adds further evidence to the association between psoriasis and AD. ${ }^{27}$

\section{Clinical aspects}

Psoriasis in children is not uncommon. To some extent, a positive family history, precipitating trigger factors, and age of onset can all predict the prognosis of the disease in children. Psoriasis in a family member has been reported in up to $71 \%$ of children with psoriasis. ${ }^{28,29}$ Identical twins have more chances of manifesting psoriasis than fraternal twins. ${ }^{30}$

\section{Age of onset}

Variations exist between studies regarding the age of onset of childhood psoriasis, ranging from 8 to 12 years. ${ }^{31,32}$ Positive family history can predict early onset of disease. ${ }^{33}$

\section{Triggering/exacerbating factors}

It has been emphasized that precipitating factors are more important in childhood onset psoriasis when compared to AOP. 5 Any form of trauma, including physical, chemical, thermal, surgical, or inflammatory, can precipitate or exacerbate psoriasis. Streptococcal infection can provoke guttate psoriasis and childhood pustular psoriasis. ${ }^{34,35}$ Like in adults, HIV infection can induce or exacerbate psoriasis. ${ }^{36}$ Although $\beta$-blocking agents and lithium are common drugs that trigger psoriasis in adults, antimalarial drugs and withdrawal of oral or potent topical corticosteroids (TCSs) play an important role in induction of rebound of psoriasis in children. ${ }^{37-39}$ Stress or lack of social support can play a major role in influencing the course of disease. ${ }^{40}$ Barisic-Drusko and Rucevic ${ }^{41}$ observed that of all the precipitating factors, the focus of inflammation was the most frequent trigger factor.

It is all the more important to identify the probable precipitating factor in all children with psoriasis.

\section{Clinical Characteristics}

Type I psoriasis has an early onset and it may therefore be appropriate to group all children under type I psoriasis.
Children with HLAs (CW6, B57, and DR7) having a positive family history may be considered to have a severe presentation and course. ${ }^{14}$ According to Morris et al, ${ }^{29}$ no sex difference was been observed in childhood psoriasis, whereas Stefanaki et $\mathrm{al}^{31}$ observed a female to male ratio of 1.4. Many authors have observed girls to be affected more than boys. ${ }^{42}$ Childhood psoriasis differs from that of the AOP by being more pruritic. The psoriatic plaques are softer and thinner in children. Scaling is also less over the plaques of childhood psoriasis. ${ }^{40}$ Mucosal involvement is rare in childhood psoriasis. ${ }^{43}$

In doubtful cases, the following features are pertinent and helpful in the clinical diagnosis of psoriasis in children: ${ }^{44}$ positive Koebner's phenomenon, positive Auspitz sign (pinpoint bleeding spot on gentle removal of scales and the Buckleys' membrane), nail pitting, and altered pigmentation with lesional clearance.

The first two features are useful to assess the disease activity.

\section{Grading}

Grading of severity of psoriasis is based on the surface area involved and other parameters such as erythema, scaling, and induration. Psoriasis area severity index (PASI) is the most widely used tool for evaluating the severity of psoriasis. In a simpler way, severity is graded taking into consideration the body surface involved as mild, moderate, and severe when $<3 \%$; 3\%-10\%; and $>10 \%$ body surface area (BSA) are involved, respectively. ${ }^{45}$

\section{Clinical types}

There seem to be many differences in the characteristics between childhood onset psoriasis and adulthood onset psoriasis. This has led to the concept of classifying psoriasis into POP and AOP. Positive family history, history of preceding streptococcal infection, and stress are found more frequently in POP than in AOP. Although age of onset in POP can be as young as infancy (as in congenital psoriasis), the mean age of onset and manifestation lies between 8 and 12 years of age.

The two major subtypes of juvenile psoriasis are psoriasis vulgaris or plaque-type psoriasis and the pustular psoriasis. Other special forms of childhood psoriasis include nail psoriasis, erythrodermic psoriasis, arthropathic psoriasis, and the SAPHO (synovitis, acne, pustulosis, hyperostosis, and osteitis) syndrome. Up to $60 \%$ of children and adolescents manifest as typical plaque psoriasis.

Under plaque-type psoriasis are embraced, palmoplantar psoriasis (plaque type), linear psoriasis, follicular psoriasis, 
guttate psoriasis, scalp psoriasis, facial psoriasis, and inverse psoriasis, which includes napkin and genital psoriasis.

\section{Plaque psoriasis}

Plaque-type psoriasis is by far the most common type of psoriasis seen in children, accounting from $30 \%$ to $60 \%$ of the total pediatric cases studied. ${ }^{31}$ Itching may be the main symptom in older children. Classical plaque psoriasis is characterized by erythema and silvery-white scales. Psoriatic plaques are raised and easily palpable, usually round to oval, irregular in shape, measuring one to several centimeters. Smaller plaques may coalesce to form large thick plaques over the legs and sacral region. These plaques when active are erythematous and exhibit distinctive rich, full red color, the salmon pink hue; however, plaques on the legs or treated plaques may sometimes appear violaceous in older children. The margins are well defined and sharply demarcated. The scales are typically dry, thin, silvery white, or micaceous. However, in dark-skinned children, both erythema and scaling are not so obvious. The lesions have a tendency for symmetry and high degree of uniformity, with minimal morphological difference between two sides. The number of lesions varies from a few to many at any given time. The common sites involved are scalp, postauricular area, elbows, knees (Figure 1), umbilical region, and buttocks. Scalp was found to be the most common site affected. ${ }^{42}$

\section{Palmoplantar psoriasis}

Palmoplantar psoriasis can be of pustular or nonpustular variant. Plaque psoriasis of the palms and soles can manifest as typical scaly, red plaques similar to psoriasis elsewhere or as thickening and scaling of the palmoplantar skin, with deep painful fissures (Figure 2). Palmoplantar psoriasis tends to be a chronic recurrent condition. In many children,

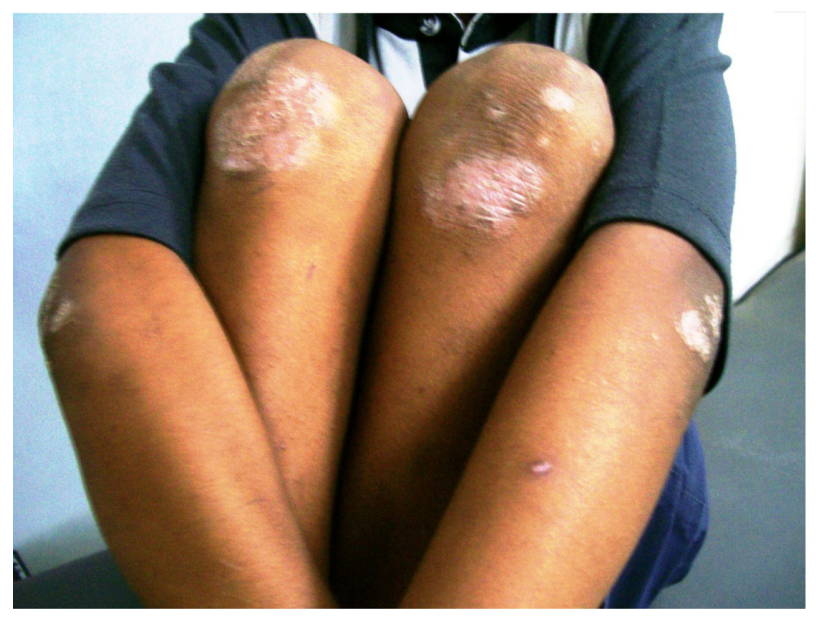

Figure I Erythematous scaly plaque of psoriasis over the knees and elbows.

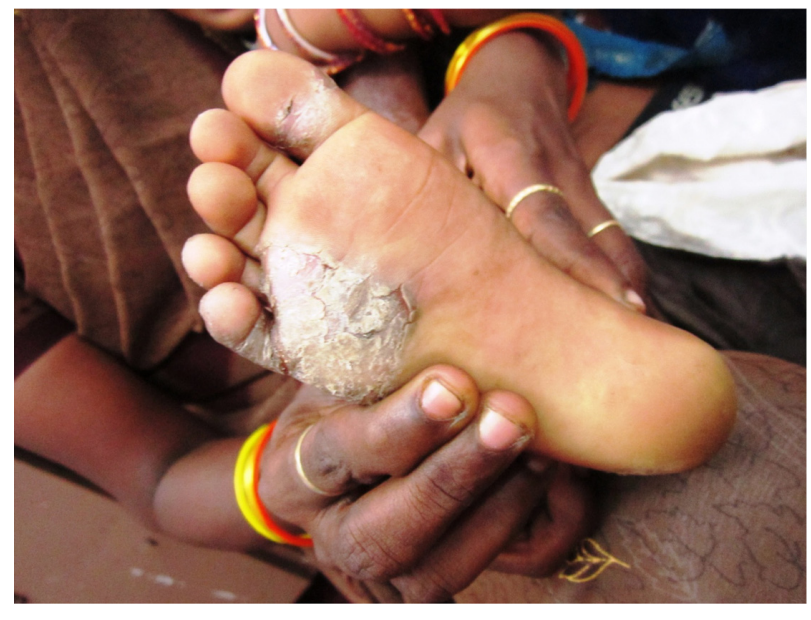

Figure 2 Thick scaly plaques with painful deep fissures.

palmoplantar psoriasis is a painful condition limiting day-to-day activities, resulting in poor school performance. Psoriasis of the palm can mimic hand eczema and may often be difficult to distinguish, as sometimes both may coexist or alternate. Well-defined margin and absence of vesiculation are clues toward psoriatic etiology. Thickened dull red skin over the knuckles is an additional finding sometimes observed in palmar psoriasis.

\section{Linear psoriasis}

Linear distribution of psoriasis can be an isolated manifestation or can be superimposed with psoriasis vulgaris. Linear plaques distributed along the imaginary lines of Blaschko (Figure 3) may be mistaken for inflammatory linear verrucous epidermal nevus (ILVEN). Intense itching and unresponsiveness to treatment are features of ILVEN, while
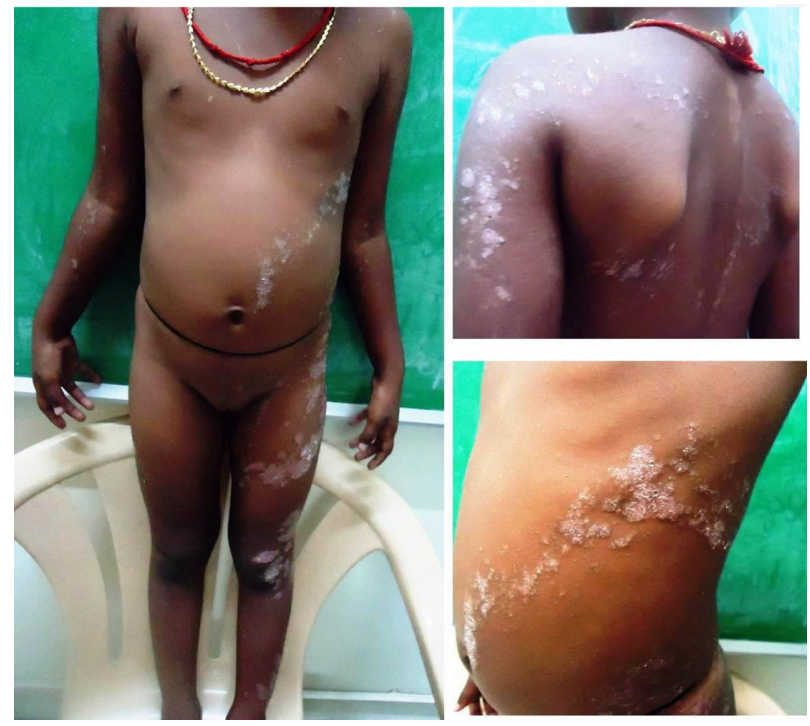

Figure 3 Erythematous scaly papules or plaques following the lines of Blaschko. 
positive family history, Koebner's phenomenon, and Auspitz sign (when present) will help clinical diagnosis, which can be further confirmed with immunohistochemical study for keratin 10 expression (which in turn is found to be increased in ILVEN but not in psoriasis).

\section{Follicular psoriasis}

Follicular psoriasis in children is characterized by the appearance of grouped asymmetrical horny follicular papules involving the trunk, axillae, and bony prominences. If the lesions are wide spread, they may resemble pityriasis rubra pilaris. Follicular psoriasis has a predilection for dark-skinned individuals and can be seen along with plaques of psoriasis vulgaris or denovo.

\section{Guttate psoriasis}

The word "Gutta" in Latin means drop. Streptococcal infection in the form of upper respiratory tract infection and perianal dermatitis often precedes the eruption by $2-3$ weeks. ${ }^{47-49}$ Guttate psoriasis has been reported following infections with Malassezia, Candida, human papilloma virus, and varicellazoster virus, retrovirus, as well as after H1N1 influenza vaccination. Drugs such as $\beta$-blocker, lithium, antimalarial and nonsteroidal anti-inflammatory drugs, and etanercept ${ }^{50}$ can precipitate guttate psoriasis.

Guttate psoriasis is clinically characterized by the sudden onset of drop-like small papule of 1-10 mm diameter. They are erythematous-to-pink in color, monomorphic, with fine scales predominantly occurring over the trunk and proximal extremities (Figure 4). Lesions spread centripetally, and new papules continue to develop lasting for 1 month. Lesions remain stable for a month and undergo remission by around the third month. A chronic course should arouse suspicion of evolution into psoriasis vulgaris.

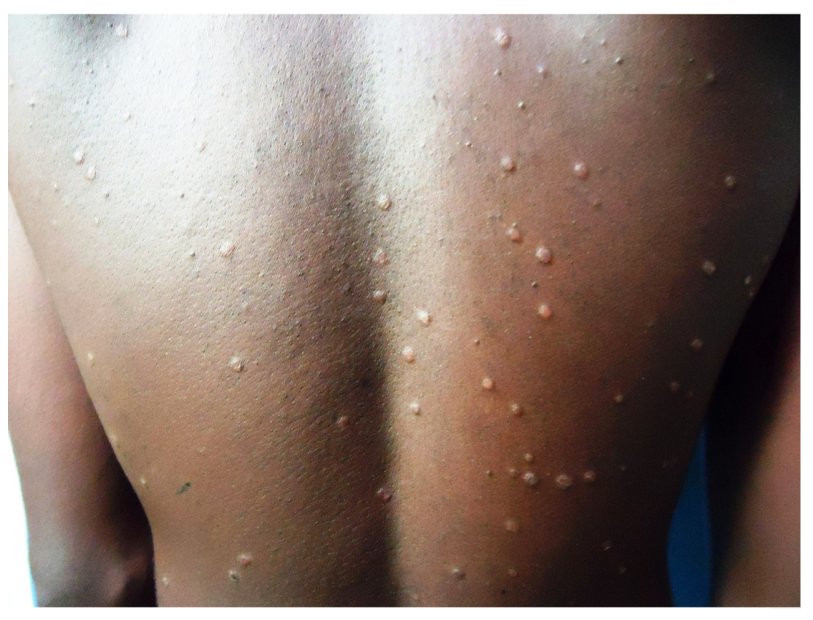

Figure 4 Erythematous, monomorphic scaly guttate papules.
Isolated bouts of eruptions unassociated with preceding infection are not uncommon.

\section{Scalp psoriasis}

Scalp is the most common site involved in psoriasis, both in children and adults, and affects $\sim 50 \%$ of patients. Itching and hair loss are common symptoms, though not seen in all. Scalp can be involved alone or as part of plaque-type psoriasis elsewhere. Circumscribed scaly plaques are sometimes the only presentation (Figure 5). The most common condition that can be confused with psoriasis is seborrhoeic dermatitis of the scalp. In psoriasis, the lesion is raised and palpable, scales are slivery white, and the plaque extends beyond the hair margin, whereas in seborrhoeic dermatitis, the scales are greasy, and the patch is limited to the hairbearing area.

\section{Facial psoriasis}

Involvement of the face in psoriasis is not uncommon. Patients with facial involvement tend to have an early onset, long duration, more extensive disease, positive Koebner responses with a positive family history, and require more intensive treatment. In view of the above observations, facial involvement can be taken as a marker of severe disease and extra efforts should be taken in managing these children, not underestimating the psychological stress caused by facial involvement. ${ }^{51}$ Mild to intense itch, soreness, or skin sensitivity are common presenting symptoms of facial psoriasis. Psoriasis faciei can manifest as one of the following three types: hairline psoriasis, sebopsoriasis, and true facial psoriasis.

Hairline psoriasis is an extension of scalp psoriasis beyond the hairline onto facial skin presenting as bright red thick scaly plaques. The sebopsoriasis manifests as patchy involvement of hairline also affecting the eyelid, eyebrows,

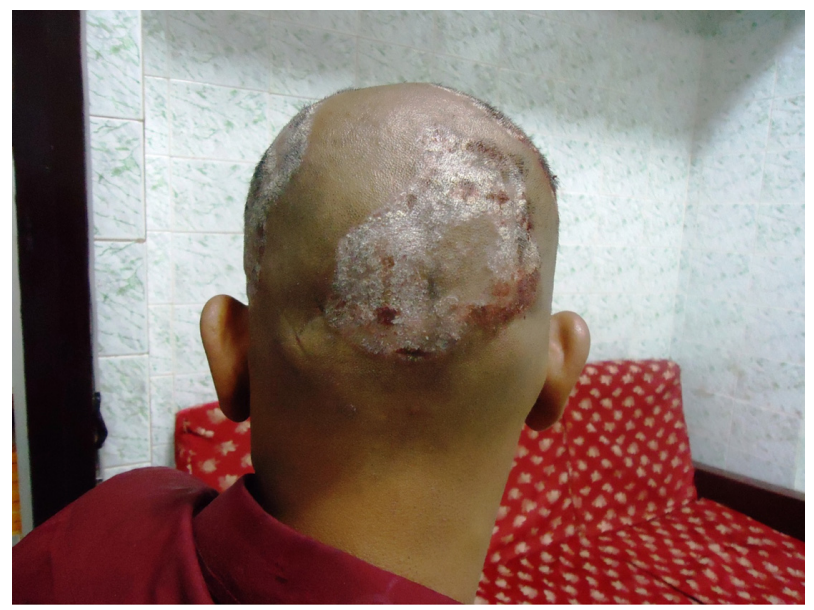

Figure 5 Circumscribed scaly plaques over the scalp. 
nasolabial folds, and beard area. Here, the lesions present as thin plaque with fine scales. True facial psoriasis can occur over any part of the face and presents as more or less symmetrical, sharply demarcated red scaly plaques (Figure 6). True facial psoriasis is invariably associated with psoriasis of other parts of the body.

True facial psoriasis is associated with psoriasis elsewhere like skin over the ear, genitals, scalp, elbows, and knees. This type of psoriasis can be a part of erythrodermic psoriasis. Rarely, facial psoriasis may also be aggravated by ultraviolet (UV) radiation and the local skin flora Malassezia.

\section{Inverse psoriasis}

Inverse psoriasis is a variant of plaque psoriasis that spares the extensor surface typically affected by psoriasis vulgaris and affects the intertriginous areas with minimal or no scaling. This includes psoriasis of the flexures, napkin area, and genital psoriasis. It is characterized by smooth, inflamed lesions without scaling (Figure 7). Flexural psoriasis may occur as a primary disorder or as an isomorphic phenomenon on preexisting infective, seborrhoeic or intertriginous dermatoses. Psoriasis should be considered a diagnosis in case of therapeutic failure of intertrigo to antibacterial or antifungal agents. Similarly, candidal intertrigo should be considered a differential as there can be candidal overgrowth in flexural psoriasis. Psoriatic plaques of flexures are anhidrotic; however, friction and maceration tend to alter the clinical picture but still retain the characteristic pink color and well-defined nonscaly borders. The plaque has a glazed appearance with fissuring at the depth of the folds. Occurrence of psoriasis of retro auricular fold and external auditory meatus are the hidden signals of psoriasis and has to be differentiated from seborrhoeic dermatitis.

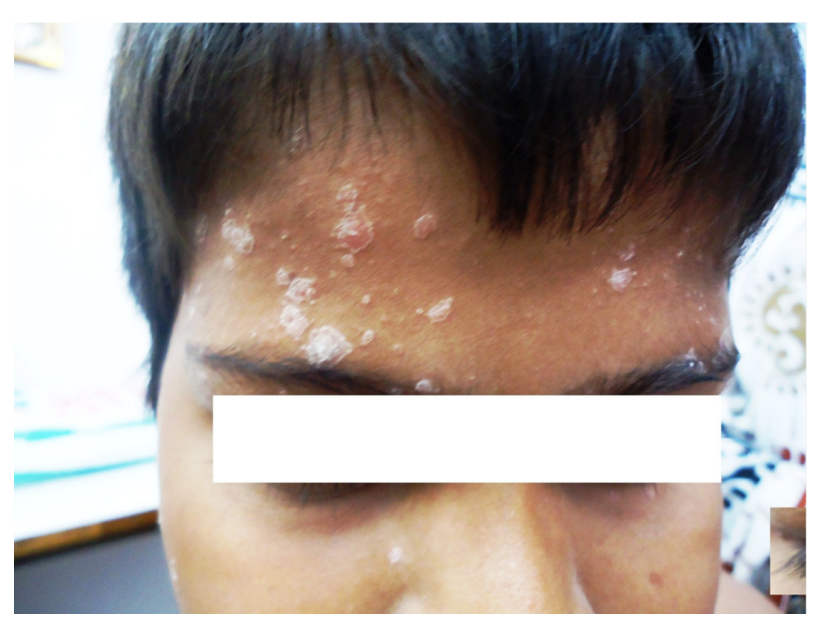

Figure 6 Sharply demarcated, red, scaly plaques over the face.

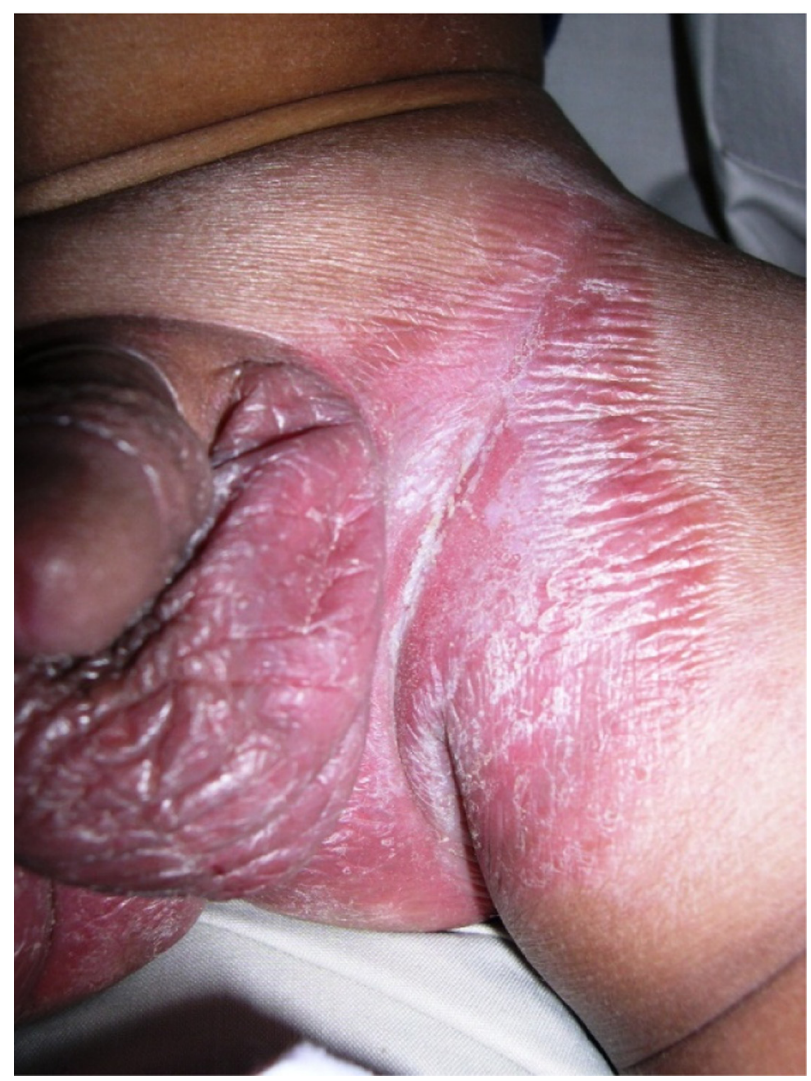

Figure 7 Erythematous smooth, inflamed skin over the groin

In infants, diaper dermatitis may be mistaken for psoriasis and vice versa. This can be followed by dissemination of the disease to involve the whole body. Hence, an eye of suspicion and early recognition are important.

Genital psoriasis affects males and females, children and adults. In children, genital psoriasis is most common under the age of 2 years, when it presents as psoriatic napkin eruption. Genital psoriasis may be part of a more generalized psoriasis, rarely making its first appearance over the genital skin (Figure 8). Genital psoriasis has multifactorial genetic and environmental causes. In the genital area, specific factors to consider include colonization by bacteria and yeasts (Candida albicans) and injury to the skin, causing new plaques of psoriasis to develop (Koebner's phenomenon). ${ }^{52,53}$

\section{Associations and comorbidities}

Psoriasis is commonly found to be associated with conditions such as eczema, vitiligo, alopecia areata, and lichen planus. ${ }^{54}$ It can also be easily mistaken for seborrhoeic dermatitis and avitaminosis, with which it can coexist. The association with AD commonly seen in adults is also seen in children with psoriasis. ${ }^{55}$ Regarding the association of systemic diseases, 


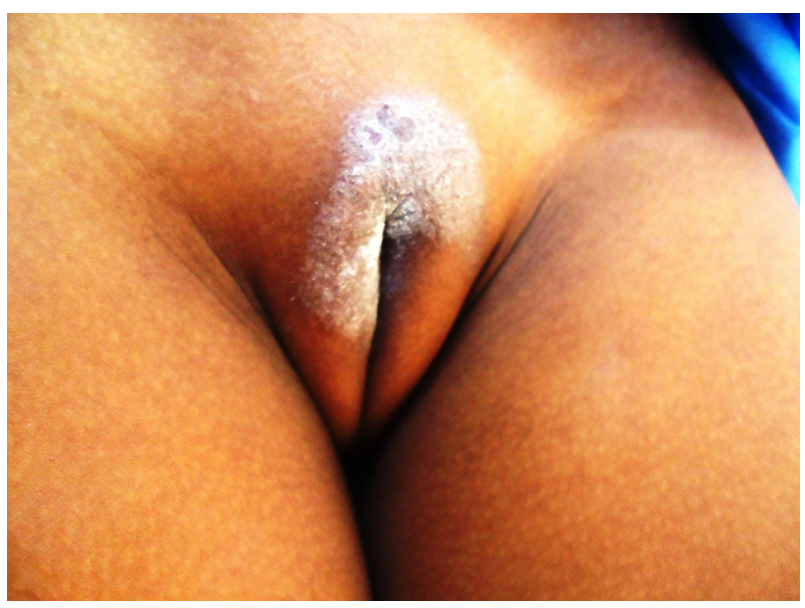

Figure 8 Scaly plaque of psoriasis as the only manifestation.

psoriatic children have a higher prevalence of obesity. It was also observed that overweight had different effects on childhood patients. Psoriasis in these children was more severe compared with psoriatic children of normal weight. ${ }^{56}$ There seems to be a strong association between psoriasis and obesity, especially in boys. ${ }^{57}$ Increased incidence of hyperlipidemia, hypertension, and diabetes has also been reported to be associated with psoriasis in children/adolescents. It may be considered that in an obese child, disease severity can be considered a marker of future cardiovascular risk. Apart from obesity, the following comorbidities were observed by Silverberg: ${ }^{7}$ Crohn's disease, ulcerative colitis, hyperlipidemia, diabetes mellitus, hypertension, ischemic heart disease, and rheumatoid arthritis. According to recent studies, comorbidities in psoriasis patients under the age of 20 years are double that of their peers without psoriasis. ${ }^{58}$ It is also observed that $32 \%$ of children and $41 \%$ of adolescents with moderate-to-severe psoriasis were overweight, which is significantly higher than the general population, ${ }^{59}$ and obesity in early adulthood may increase the risk of developing psoriatic arthritis later in life. ${ }^{60}$

\section{Treatment}

Therapy of childhood psoriasis of any type is demanding. Certain factors that are peculiar in children, such as their body metabolism and physical development (which are different from that of the adults), and the cutaneous absorption and pharmacodynamics and pharmacokinetics of drugs (which are far variable when compared to those in adults) make safe and effective treatment of psoriasis a challenge. Chronicity of the disease and the recurring nature should be kept in mind while considering long-term therapy with topical and systemic drugs. Advice on phototherapy should be critically judged, keeping in mind the long years of sun exposure the children are prone to. Thus treatment of childhood psoriasis is a cause for concern to the child, the parent, and the doctor alike. An effective therapy starts with counseling the patient and the parent, explaining to them the nature of the disease, treatment options available, their pros and cons.

This segment will review the treatment of childhood psoriasis under two headings, the treatment options available and treatment of different types of psoriasis.

Treatment options available can be symptomatic and specific. Antihistamines are given to alleviate itching. It would therefore be preferable to give sedative antihistamines.

The available treatment options are broadly divided as: topical therapy, phototherapy, systemic therapy and other modalities.

\section{Topical therapy}

The limitations of a safe systemic therapy lead to a distinctly greater role of topical therapy in children even for moderate and some cases of severe psoriasis. Despite advancement in the armamentarium of systemic drugs, including the advent of biologics, topical therapy seems sensible for a vast majority of children with psoriasis. These topical agents are used exclusively or in combination with systemic therapy, depending on the individual's requirement. Since psoriasis is a chronic inflammatory disease with remissions and exacerbations, often requiring prolonged therapy, the choice of topical therapy should be made taking into consideration the long-term side effects, with particular reference to steroids, and topical immune-suppressive agents. Higher penetration capacity of children's skin, due to the altered ratio of skin surface area to body weight, demands further attention while considering topical agents, with particular reference to steroid molecules. The primary goal in the treatment of childhood psoriasis is effective control of disease and not complete clearance. Apart from emollients, corticosteroids and anthralin are the topical agents licensed for use in children with psoriasis. In case of contemplating other drugs lacking approval, patient and parents must be comprehensively informed about all details, including long-term side effects, before the initiation of therapy.

Topical therapy is the mainstay for mild or localized disease with a PASI $<10$ or involvement of BSA of $<20 \%$.

Emollients, moisturizers, keratolytics, tar, anthralin, corticosteroids, Vitamin D analogs, calcineurin inhibitors, and retinoid are various topical preparations available.

The choice will depend upon the age of the child, type of psoriasis, PASI score, site of involvement, other 
comorbidities and associations, tolerance, and affordability. Use of keratolytics, keratoplastic, and antipruritic topical agents may be considered in selected cases in order to get better results within a shorter period. In children $<2$ years of age, emollients and mild corticosteroids are safe, while moderate and high potent steroids are reserved for children between the age of 2 and 12 years and $>12$ years, respectively. Keratolytics are useful in treating thick plaques and plantar psoriasis but should be used with caution in children.

Topical therapy should be followed by regular skin care during remission period. Urea in different concentrations in a lipophilic cream base can be used as emollient, antipruritic, and or keratolytics in selected children for a limited period.

\section{Emollients}

Emollients are the most commonly used topical agents in the management of childhood psoriasis. White soft paraffin can reduce transepidermal water loss, soothe and soften the skin, and reduce scaling. Emollients improve the hydration of the stratum corneum, thereby enhancing the barrier function. A well-hydrated epidermis is less amenable to physical trauma and stress, which is a common disease-exacerbating factor. In young children, it is wise to initiate treatment with any of the above agents and wait for the disease to evolve before embarking on any stronger medications having side effects.

\section{Keratolytics}

Keratolytics are capable of reducing scaling and thereby enhance absorption of other drugs. Salicylic acid and urea are common keratolytics used in children with thick plaque psoriasis. These agents should be used with great caution in children as systemic absorption is much higher than in adults. Even small amounts of salicylic acid can lead to central nervous system side effects or renal damage that can be fatal. In children under 6 years of age, these agents should be used only over small areas in a maximum concentration of $0.5 \%$. Salicylic acid can be used to treat thick lesions over the scalp, palms, and soles in children older than 6 years, and is best avoided in younger children due to potential risk of salicylism resulting from percutaneous salicylate absorption. ${ }^{61}$ Salicylic acid preparations should be avoided before phototherapy, as the filtering effect of topical salicylic acid reduces the efficacy of UVB therapy.

\section{Tar}

Coal tar has both antipruritic and anti-inflammatory effects. It also suppresses DNA synthesis and acts as antiproliferative agent. ${ }^{62,63}$ It is used alone or in combination with other agents such as corticosteroids, salicylic acid, and UV therapy. Tar causes irritation, when combined with UV light as in Goeckerman regimen. Tar is also known to induce chromosomal aberration in peripheral lymphocytes and bring out release of heat shock proteins. ${ }^{64}$ Tar should not be used on face and flexures and in children below 12 years of age.

\section{Dithranol}

Dithranol (anthralin) has anti-inflammatory and antiproliferative effects, which are attributable to its ability to regulate keratinocyte differentiation and prevent T-lymphocyte activation. The drug accumulates in the epidermal keratinocyte mitochondria and dissipates mitochondrial membrane potential. These changes lead to induction of apoptosis through a pathway dependent on respiratory-competent mitochondria. ${ }^{65}$ "Short contact therapy" is the preferred method in which increasing concentrations of anthralin are applied for a short period (10-30 minutes) of time till slight irritation develops, at which point the dose and time are held constant till the clearance of lesions. ${ }^{66} \mathrm{~A}$ significant remission in $81 \%$ of children was observed with $1 \%$ concentration. ${ }^{67}$ It can be combined with UVB phototherapy, as in Ingram technique, to improve the efficacy. Anthralin (1\%) or dithranol is rarely used alone as it causes irritation. ${ }^{68}$ The usage of dithranol has been reducing with the advent of cosmetically acceptable topical preparations.

\section{Topical corticosteroids}

TCSs have been in use since 1952 with the introduction of hydrocortisone, when they were used as anti-inflammatory agents with remarkable efficacy. TCS are the most frequently employed topical agents, especially in itchy plaques. Topical steroids are suitable for treating childhood psoriasis among all age groups ( $>2$ months of age). They possess antiinflammatory, antiproliferative, immunosuppressive, and vasoconstrictive effects. According to the WHO classification, TCS have been ranked in terms of potency into four groups consisting of seven classes. Class I TCS are the most potent, whereas class VII TCS are the least. While choosing the potency, low-to-mid-potent TCS of classes V-VII are preferred for facial and intertriginous skin, whereas mild potency TCS of classes II-IV are preferred for extremities and scalp. ${ }^{69}$ With judicious use of TCS, most of the side effects can be averted. Rapid recurrence after discontinuation of therapy is seen even with well-tailored therapy. TCS treatment should not be abruptly discontinued for the above reasons and for fear of developing pustular lesions. Highly potent TCS should not be used over the face, genitals, and 
in intertriginous regions. While using high potent TCS over other sites in older children, they should not be prescribed for more than 2 weeks. Clobetasol propionate can be used in children above 12 years for thick skin like sole or for thick plaques. ${ }^{70}$ Inadvertent and long-term use of TCS can lead to local infections, skin atrophy, telangiectasia, striae, acneiform eruption, and purpura. Contact dermatitis to the molecule or the vehicle is not uncommon. Rebound and tachyphylaxis are to be remembered while using topical steroids for a prolonged period. To use the correct quantity, it is always advisable to follow the fingertip unit and adhere to the schedule.

Systemic side effects are more common in children because of a higher skin surface body mass ratio when compared to adults. Selection of correct formula is of paramount importance to prevent complications. Ointments are to be avoided in flexural, facial, and genital skin. Lotions are preferred for hairy scalp. TCS can also be combined with other topical agents such as calcipotriol and tazarotene to enhance efficacy and reduce irritation. One should remember that the absorption is variable in different anatomical sites. Skin over the eyelids absorbs the most (30\%) while that of the sole absorbs the least (0.05\%). Skin over the face, armpit, forearm, and palm absorb $7 \%, 4 \%, 1 \%$, and $0.1 \%$, respectively.

\section{Topical vitamin D analogs}

Topical vitamin D analogs have anti-inflammatory and antiproliferative actions. They also induce downregulation and correction of keratinocyte differentiation. Calcipotriol, calcitriol, maxacalcitol, and tacalcitol are the various vitamin D analogs found useful in treating plaque psoriasis. When combined with betamethasone, the effect is better than either agent used alone. UVB phototherapy increases the efficacy of calcipotriol. ${ }^{71}$ The most common adverse events are burning and stinging sensation. Topical vitamin $\mathrm{D}$ analog is safe when the total dose does not exceed the recommended dose of $75 \mathrm{~g} / \mathrm{wk}$ for children above the age of 12 years; and $50 \mathrm{~g} / \mathrm{wk}$ for children between 6 and 12 years of age. Calcipotriene or calcitriol is advised for childhood psoriasis, the latter is better tolerated by sensitive skin. ${ }^{72,73}$ Clinical response with vitamin $\mathrm{D}$ are evident after 2 weeks of treatment, and a maximum effect is observed in 6-8 weeks time. Mild irritation can be reported during initial days of therapy, and this usually fades during further course of treatment. Overuse of topical vitamin D analogs can lead to hypocalcemia.

\section{Calcineurin inhibitors}

Topical calcineurin inhibitors (TCIs) act as nonsteroidal immunomodulatory drugs. They inhibit interleukin-2
(IL-2) production and subsequent T-cell activation and their proliferation by blocking the enzyme calcineurin. Tacrolimus and pimecrolimus are the two molecules belonging to this class, which although not approved by the US Food and Drug Administration, have proven efficacy. This has recently been documented for treatment of childhood psoriasis. ${ }^{74,75}$ They can be used as steroid-sparing agents and are also useful for sequential and rotational regimens, so as to avoid the adverse effects of prolonged use of TCS. TCI are useful for sites such as face, flexures, and anogenital region, where TCS cannot be used with safety. Use of TCI in children $<2$ years of age is not approved by US Food and Drug Administration. ${ }^{76}$

\section{Retinoids}

Topical retinoids are useful agents in treating plaque psoriasis in older children. Tazarotene is a third-generation retinoid that acts on keratinocyte differentiation, diminishing hyperproliferation, and also decreases expression of inflammatory markers. Skin irritation is the most common side effect, and its use is thus restricted to thicker plaques in the nonintertriginous sites. Tazarotene $0.05 \%$ gel has been successfully used to treat nail psoriasis in a child. ${ }^{77}$

\section{Eosin and oil of cade}

Topical preparation of $2 \%$ eosin alone or in combination with oil of cade is effective in the treatment of flexural/napkin psoriasis in children. Their anti-inflammatory property and cost effectiveness can be made use of in places where topical steroids cannot be used for a prolonged period.

\section{Combinations of topical agents}

Effective combinations in the management of psoriasis help to: achieve rapid cure, reduce the need for prolonged treatment with TCS, reduce side effects of TCS and reduce duration and cost of therapy.

Such combinations include: TCS with antibiotic/ antifungal agents, vitamin D3, salicylic acid, tar, and UVB; dithranol with UVB, and tar with salicylic acid and UVB.

It is worthwhile remembering that calcipotriol should be applied only after phototherapy due to its photolytic degradation and its property as a light filter. Similarly, pretreatment with salicylic acid can inactivate calcipotriol, and they should not be combined.

\section{Phototherapy}

UV radiation in the spectrum of UVA and UVB acts by inhibiting DNA synthesis as well as by bringing down keratinocyte proliferation and T-cell apoptosis. They also 
exhibit immunosuppressive and anti-inflammatory properties. The three spectra used in the treatment of psoriasis are UVA 320-400 nm, Broadband UVB (BB-UVB, 290-320 nm), and narrowband UVB (NBUVB, $311 \pm 2 \mathrm{~nm}$ ). Choice of phototherapy is appropriate for children with psoriasis involving $15 \%-20 \%$ BSA having refractory course. Focal debilitating palmoplantar psoriasis is ideal for UVB therapy in children. Of the different types of psoriasis, the guttate type responds best to phototherapy. NBUVB is the safest of the three and is used in children above 6 years of age.

UVA or psoralens UVA (PUVA) therapy is not advisable in children below 12 years of age. PUVA bath treatment should be preferred to oral PUVA in children above 12 years while treating recalcitrant palmoplantar psoriasis. This helps to avoid gastrointestinal side effects, the need for eye protection, and the advantage of short exposure time. ${ }^{78}$ NB-UVB is less carcinogenic, and given the independence of psoralens-associated side effects, this spectrum of UV light is considered the first-line phototherapy in treating childhood psoriasis. In combination with systemic agents such as calcipotriol, tazarotene will, to some extent, limit the cumulative UV exposure, thereby reducing the risk of carcinogenicity of the UV rays. ${ }^{79}$ Phototherapy must be administered by trained and skillful staff in an appropriate environment, with all protection and constant supervision. One has to remember that any form of light therapy has to be commenced in children with enough considerations and thoughtfulness of the child being exposed to UV light-containing sunlight for many more years to come in their lifetime.

\section{Systemic therapies}

Specific systemic treatment is rarely used in childhood psoriasis as a first-line therapy. Systemic therapy, including retinoid, methotrexate, cyclosporine, and biologic agents, are used only in severe forms of psoriasis or extensive plaque psoriasis with impending erythroderma. By and large, systemic immunomodulators are used in erythrodermic, pustular, and arthropathic variants of childhood psoriasis. ${ }^{80}$

The indication for systemic therapy should be one or more of the following: Involvement of BSA $>20 \%$; PASI $>10$; erythrodermic psoriasis, with or without metabolic complication; generalized pustular psoriasis; psoriatic arthropathy, and localized disease not responding to topical therapy alone or with significant psychological morbidity, putting at risk the routine day-to-day work.

\section{Retinoids}

Etretinate and acitretin, belonging to second-generation retinoids, are the most commonly used systemic retinoids in children. The modes of action, apart from the anti-inflammatory property, include modulation of the keratinocyte proliferation and differentiation. To begin with, a low dose is started, which can be increased up to $1 \mathrm{mg} / \mathrm{kg} / \mathrm{d}$, and on improvement, the dose is tapered to $0.2 \mathrm{mg} / \mathrm{kg} / \mathrm{d}$ and continued for approximately 2-3 months postremission. Absorption is increased by milk, fatty foods, and when dissolved in edible oils. ${ }^{81}$ Xerosis, cheilitis, and epistaxis are the common side effects observed. These and the alteration in the liver enzyme and serum lipid levels are reversible on cessation of therapy. Premature closure of epiphysis limits the use of retinoids in children. Retinoids are best avoided while treating girls.

\section{Methotrexate}

It is an antimetabolite agent and the most commonly used systemic drug in the treatment of psoriasis in children due to its efficacy, affordability, and convenient dosing. It is given in a dosage of $0.2-0.4 \mathrm{mg} / \mathrm{kg} / \mathrm{wk}^{82}$ Methotrexate is well tolerated by children and is effective as a single weekly oral dose. Nausea and vomiting are common side effects. ${ }^{83}$ Serious adversities are at rare occurrence. Carefully monitored administration of methotrexate in appropriately selected child is safe and effective in severe form of childhood plaque psoriasis. Obesity should be considered a relative contraindication even in children. ${ }^{84,85}$ Other relative contraindications for the use of methotrexate include renal dysfunction, hepatitis, cirrhosis and abnormal liver function tests, significant pulmonary disease, blood dyscrasias (such as anemia, leukopenia, and thrombocytopenia) and active chronic infectious diseases (such as tuberculosis).

\section{Cyclosporine}

Cyclosporine, an effective drug in the management of childhood psoriasis, primarily acts by inhibiting T-cell function and IL-2 and is generally well tolerated. ${ }^{86}$ It is used in a dose range of $3-5 \mathrm{mg} / \mathrm{kg}$ and is variably effective. In some patients, it is a true crisis buster. Nephrotoxicity, hypertension, and immunosuppression are the major side effects, and hence the drug is reserved only for severe cases. ${ }^{87,88}$ Some children may need a follow-up treatment with methotrexate after controlling the severity of disease with cyclosporine.

\section{Biologics}

The introduction of biologics in the armamentarium of antipsoriatic drugs is indeed a giant leap in the management of refractory pediatric psoriasis, where other drugs such as retinoids, methotrexate, and cyclosporine cannot be used. 
Etanercept, an antitumor necrosis factor fusion protein, has been the one studied most extensively. ${ }^{89-91}$ It has been found to be effective and well tolerated in moderate to severe plaque psoriasis in children and adolescents where other drugs fail or cannot be used. Adalimumab has been approved in Europe for children above 4 years of age suffering from severe chronic plaque psoriasis. There are reports of the use of infliximab in pediatric psoriasis, with good results. ${ }^{92-94}$ There is a case report on the successful use of ustekinumab in a 14-year-old boy with plaque psoriasis. ${ }^{95}$

Of the available biologics, etanercept (for children above 6 years of age in the dose of $0.8 \mathrm{mg} / \mathrm{kg}$ weekly), adalimumab (for children above 4 years of age in the dose of $0.4-0.8 \mathrm{mg} / \mathrm{kg}$ on alternate weeks), and ustekinumab (for children/adolescents above 12 years of age in the dose of $45 \mathrm{mg}$ monthly for 2 months followed by once in 12 weeks, administered subcutaneously) have been approved for the treatment of plaque psoriasis.

When treating a child with biologics, parents should be cautioned about the side effects and potential lifethreatening complications, which can be associated with the treatment. Being an immunosuppressive drug, the dosing of the biologic agent is crucial ensuring that the child's immune system is not suppressed and allows for contacting infectious disease. Administration of any of the above systemic drugs in a child should always be a team effort of dermatologist and pediatrician, along with other specialists whenever necessary. Before contemplating on treatment with newer biologics, the long-term side effects and the cost should be weighed, with the remission period offered by the drugs. Any such cost-effective drug with fewer side effect and longer remission period will be a promising option for the years to come.

\section{Other modalities LASER}

Use of LASER (light amplification by stimulated emission of radiation) in the management of childhood psoriasis is a safe mode, which is devoid of the complications of phototherapy with UVA and UVB rays. A pilot study has reported safety and efficacy of $308 \mathrm{~nm}$ excimer LASER in the localized treatment of psoriasis in children. ${ }^{96}$

\section{Antibiotics}

Oral antibiotics are indicated in guttate psoriasis with proven streptococcal etiology. They are also useful in psoriasis vulgaris, particularly in the setting of a positive culture from the throat swab and in the presence of perianal bacterial dermatitis in pustular psoriasis. ${ }^{97}$

\section{Dietary supplement}

Role of diet in the management of psoriasis is controversial. However, it is important to advise obese children on diet restriction and weight reduction. Fish oil, rich in $\omega-3$ fatty acids, is the best-known dietary supplement ${ }^{98}$ for patients with psoriasis. There is an anecdotal report of Indigo naturalis, a Chinese medicine gives good results when used topically, formulated as an ointment. ${ }^{99}$

\section{Role of tonsillectomy}

Though the evidences pointing toward the advantage of tonsillectomy in childhood psoriasis are not consistent, tonsillectomy may be considered in those children with recurrent tonsillitis that is proved to either trigger, maintain, or worsen psoriasis.

\section{Psychological aspects and rehabilitation}

Psoriasis by itself is a disease that causes a lot of psychological stress (and vice versa).

A study found that in children with psoriasis the stress was as high as in children with $\mathrm{AD}$, and higher than in children with urticaria or acne. ${ }^{100}$ In studies on quality of life in children with different skin diseases, those with psoriasis reported the greatest impairment in quality of life. ${ }^{101,102}$

Rehabilitation of children with psoriasis should supplement therapy wherever necessary. The goals of rehabilitation therapy must include the following: regular treatment under proper supervision clubbed with climatic and nutritional therapies; appropriate psychological intervention; necessary help in coping with the disease with respect to psychological consequences of the illness, and help in finding a suitable occupation as they grow.

\section{Treating pediatric plaque psoriasis: challenges and solutions}

1. Presentation of disease is different from that in adults

a. The incidence of guttate psoriasis is more frequent than in adults, needing an appropriate antibiotic therapy in children.

b. Psoriatic plaques of children show lesser amount of scaling than that seen in adults, and hence it is preferable to avoid keratolytics alone or in combination unless indicated.

c. There can be an overlap of napkin psoriasis with diaper dermatitis or the former can be mistaken for the latter (and vice versa). This needs astute clinical examination, relevant investigation, and appropriate selection of drug. 
2. Peculiarities with reference to physical status

a. Increased BSA in relation to weight in children leads to increased absorption of topical medication applied. This has to be borne in mind while using topical agents, especially steroids. It is advisable to adhere to fingertip units while prescribing TCS.

b. Thin skin of children also leads to increased absorption of topical medications. Judicious use of topical steroids by selecting the correct potency will help avoid complications due to inadvertent use of TCS in children.

c. Since the immature liver of children cannot metabolize certain systemic drugs, it is better to keep systemic therapy as the last resort. Systemic agents should be considered only in severe cases not responding to conventional therapy and should be instituted under strict supervision.

d. In view of the immature status of the kidneys to excrete drugs, strict biochemical monitoring is suggested while contemplating systemic drugs in children.

e. Children have an active hematopoietic system that can be easily be affected with antimitotic drugs. Hence, periodic blood count has to be performed in children requiring antimitotic agents.

3. Peculiarities with reference to mental status

a. There is significant element of poor adherence to therapy in adolescence and children. This is a real challenge, which has to be overcome by adequate counseling.

b. Peer pressure plays a negative role in handling the disease. This again can be overcome by counseling.

4. Evidences about usage of any particular drug in pediatric age group

a. Only few controlled studies and double-blind studies are available in the field of therapy of childhood psoriasis. More such studies should be encouraged and documented.

b. Only a few licensed molecules are available for pediatric age group. It is a hope to get better and safer licensed molecules in future which are cost-effective as well.

5. Lifestyle of todays children.

Lifestyle modification holds the key to success in controlling the disease, be it in adult, adolescent, or child. Children must be encouraged to get involved in active physical exercise and adhere to healthy dietary habits.

\section{Summary}

Childhood psoriasis signifies a special challenge. Early diagnosis and appropriate management will avoid comorbidities that are likely to develop in adulthood due to chronic inflammation. Aggressive therapy should be considered in children with severe psoriasis in whom intermittent therapy has failed to control the disease.

\section{Disclosure}

The authors report no conflicts of interest in this work.

\section{References}

1. Sharma V, Orchard D. Paediatric psoriasis. Paediatr Child Health. 2011;21(3):126-131.

2. Psoriasis 'substantial burden' on UK healthcare. Arch Dermatol. 2005;141:1537-1541. Abstract available from: https://www.medwirenews. com/psoriasis/dermatology/psoriasis-substantial-burden-on-uk-healthca re/174608? searchBackButton=true\#. Accessed February 3, 2016.

3. de Jager ME, de Jong EM, Meeuwis KA, van de Kerkhof PC, Seyger MM. No evidence found that childhood onset of psoriasis influences disease severity, future body mass index or type of treatments used. J Eur Acad Dermatol Venereol. 2010;24(11): 1333-1339.

4. Swanbeck G, Inerot A, Martinsson T, et al. Age at onset and different types of psoriasis. Br J Dermatol. 1995;133(5):768-773.

5. Raychaudhuri SP, Gross J. A comparative study of pediatric onset psoriasis with adult onset psoriasis. Pediatr Dermatol. 2000;17(3): 174-178.

6. Farber EM, Mullen RH, Jacobs AH, Nall L. Infantile psoriasis: a follow up study. Pediatr Dermatol. 1986;3(3):237-243.

7. Silverberg NB. Pediatric psoriasis: an update. Ther Clin Risk Manag. 2009;5:849-856.

8. Kumar B, Jain R, Sandhu K, Kaur I, Handa S. Epidemiology of childhood psoriasis: a study of 419 patients from northern India. Int $J$ Dermatol. 2004;43(9):654-658

9. Häfner R, Michels H. Psoriatic arthritis in children. Curr Opin Rheumatol. 1996;8(5):467-472.

10. Li Y, Begovich AB. Unraveling the genetics of complex diseases: susceptibility genes for rheumatoid arthritis and psoriasis. Semin Immunol. 2009;21(6):318-327.

11. Lowes MA, Kikuchi T, Fuentes-Duculan J, et al. Psoriasis vulgaris lesions contain discrete populations of Th1 and Th17 T cells. J Invest Dermatol. 2008;128(5):1207-1211.

12. Hüffmeier U, Lascorz J, Becker T, et al. Characterization of psoriasis susceptibility locus 6 (PSORS6) in patients with early onset psoriasis and evidence for interaction with PSORI. J Med Genet. 2009;46(11):736-744.

13. Schäfer T. Epidemiology of psoriasis. Review and the German perspective. Dermatology. 2006;212(4):327-337.

14. Henseler T. The genetics of psoriasis. J Am Acad Dermatol. 1997;37(2):S1-S11.

15. Schwartz RA, Zalewska A, Erdal E. Cutaneous manifestations of HIV. April 2015. Available from: http://emedicine.medscape.com/ article/1133746-overview\#a11. Accessed February 3, 2016.

16. Takahashi H, Tsuji H, Takahashi I, et al. Plasma adiponectin and leptin levels in Japanese patients with psoriasis. Br J Dermatol. 2008;159(5):1207-1208.

17. Takahashi H, Tsuji H, Takahashi I, et al. Prevalence of obesity/adiposity in Japanese psoriasis patients: adiposity is correlated with the severity of psoriasis. J Dermatol Sci. 2009;54(1):61-63.

18. Eaton LH, Chularojanamontri L, Ali FR, Theodorakopoulou E, Dearman RJ, Kimber I. Guttate psoriasis is associated with an intermediate phenotype of impaired Langerhans' cell migration. Br J Dermatol. 2014;171(2):409-411.

19. Leclerc-Mercier S, Bodemer C, Bourdon-Lanoy E, et al. Early skin biopsy is helpful for the diagnosis and management of neonatal and infantile erythrodermas. J Cutan Pathol. 2010;37(2): 249-255. 
20. Wollenberg A, Wagner M, Günther S, et al. Plasmacytoid dendritic cells: a new cutaneous dendritic cell subset with distinct role in inflammatory skin diseases. J Invest Dermatol. 2002;119(5):1096-1102.

21. Chen SC, de Groot M, Kinsley D, et al. Expression of chemokine receptor CXCR3 by lymphocytes and plasmacytoid dendritic cells in human psoriatic lesions. Arch Dermatol Res. 2010;302(2):113-123.

22. Sano S, Chan KS, Carbajal S, et al. Stat3 links activated keratinocytes and immunocytes required for development of psoriasis in a novel transgenic mouse model. Nat Med. 2005;11(1):43-49.

23. Beer WE, Smith AE, Kassab JY, Smith PH, Rowland Payne CM. Concomitance of psoriasis and atopic dermatitis. Dermatology. 1992;184(4):265-270.

24. Guttman-Yassky E, Nograles KE, Krueger JG. Contrasting pathogenesis of atopic dermatitis and psoriasis - part II: immune cell subsets and therapeutic concepts. J Allergy Clin Immunol. 2011;127(6):1420-1432.

25. Giustizieri ML, Mascia F, Frezzolini A, et al. Keratinocytes from patients with atopic dermatitis and psoriasis show a distinct chemokine production profile in response to T cell-derived cytokines. JAllergy Clin Immunol. 2001;107(5):871-877.

26. Cookson WO, Ubhi B, Lawrence R, et al. Genetic linkage of childhood atopic dermatitis to psoriasis susceptibility loci. Nat Genet. 2001;27(4):372-373.

27. Parimalam K, Thomas J. Congenital erythrodermic psoriasis with atopic dermatitis: an example of immunogenetic spinoff. Indian J Pathol Microbiol. 2013;56(1):72-73.

28. Seyhan M, Coskun BK, Sağlam H, Ozcan H, Karincaoğlu Y. Psoriasis in childhood and adolescence: evaluation of demographic and clinical features. Pediatr Int. 2006;48(6):525-530.

29. Morris A, Rogers M, Fischer G, Williams K. Childhood psoriasis: a clinical review of 1262 cases. Pediatr Dermatol. 2001;18(3):188-198.

30. Grjibovski AM, Olsen AO, Magnus P, Harris JR. Psoriasis in Norwegian twins: contribution of genetic and environmental effects. J Eur Acad Dermatol Venereol. 2007;21(10):1337-1343.

31. Stefanaki C, Lagogianni E, Kontochristopoulos G, et al. Psoriasis in children: a retrospective analysis. J Eur Acad Dermatol Venereol. 2011;25:417-421.

32. al-Fouzan AS, Nanda A. A survey of childhood psoriasis in Kuwait. Pediatr Dermatol. 1994;11(2):116-119.

33. Altobelli E, Petrocelli R, Marziliano C, et al. Family history of psoriasis and age at disease onset in Italian patients with psoriasis. Br J Dermatol. 2007;156(6):1400-1401

34. Honig PJ. Guttate psoriasis associated with perianal streptococcal disease. J Pediatr. 1988;113(6):1037-1039.

35. Cassandra M, Conte E, Cortez B. Childhood pustular psoriasis elicited by the streptococcal antigen: a case report and review of the literature. Pediatr Dermatol. 2003;20(6):506-510.

36. Lazar AP, Roenigk HH Jr. Acquired immunodeficiency syndrome (AIDS) can exacerbate psoriasis. J Am Acad Dermatol. 1988;18(1 Pt 1) 144.

37. Tsankov N, Angelova I, Kazandjieva J. Drug-induced psoriasis. Recognition and management. Am J Clin Dermatol. 2000;1(3):159-165.

38. Wolf R, Ruocco V. Triggered psoriasis. Adv Exp Med Biol. 1999;455:221-225.

39. O'Brien M, Koo J. The mechanism of lithium and beta-blocking agents in inducing and exacerbating psoriasis. J Drugs Dermatol. 2006; 5(5):426-432.

40. Benoit S, Hamm H. Childhood psoriasis. Clin Dermatol. 2007;25(6): 555-562.

41. Barisic-Drusko V, Rucevic I. Psoriasis in childhood. Coll Anthropol. 2004;1:211-285.

42. Wu Y, Lin Y, Liu HJ, Huang CZ, Feng AP, Li JW. Childhood psoriasis: a study of 137 cases from central China. World J Pediatr. 2010;6: 260-264.

43. Nanda A, Kaur S, Kaur I, Kumar B. Childhood psoriasis: an epidemiological survey of 112 patients. Pediatr Dermatol. 1990;7:19-21.

44. Stern RS, Wu J. Psoriasis. In: Arndt KA, LeBoit PE, Robinson JK, Wintroub BU, editors. Cutaneous Medicine and Surgery. Philadelphia, PA: WB Saunders; 1996.
45. Gottlieb AB, Chaudhari U, Baker DG, Perate M, Dooley LT. The National Psoriasis Foundation Score (NPF-PS) system versus the Psoriasis Area Severity Index (PASI) and Physicians Global Assessment (PGA): a comparison. J Drugs Dermatol. 2003;2(3):260-266.

46. Thomas LJ, Dadzie $O E$, Francis N, Morar N. Follicular psoriasis a forgotten entity? Open Dermatol J. 2010;4(3):95-96.

47. Nahary L, Tamarkin A, Kayam N, et al. An investigation of antistreptococcal antibody responses in guttate psoriasis. Arch Dermatol Res. 2008;300(8):441-449.

48. Ulger Z, Gelenava T, Kosay Y, Darcan S. Acute guttate psoriasis associated with streptococcal perianal dermatitis. Clin Pediatr (Phila). 2007;46(1):70-72.

49. Ledoux M, Chazerain V, Saiag P, Mahe E. [Streptococcal perianal dermatitis and guttate psoriasis]. Ann Dermatol Venereol. 2009; 136(1):37-41.

50. Altman K, Bennett DD, Butler DF. Guttate psoriasis. Available from: http://emedicine.medscape.com/article/1107850. Accessed February 3, 2016.

51. Canpolat F, Cemil BC, Eskioğlu F, Akis HK. Is facial involvement a sign of severe psoriasis? Eur J Dermatol. 2008;18(2):169-171.

52. Guglielmetti A, Conlledo R, Bedoya J, Ianiszewski F, Correa J. Inverse psoriasis involving genital skin folds: successful therapy with dapsone. Dermatol Ther. 2012;2(1):15.

53. Wang G, Li C, Gao T, Liu Y. Clinical analysis of 48 cases of inverse psoriasis: a hospital-based study. Eur J Dermatol. 2005;15:176-178.

54. Pagliarello C1, Fabrizi G, Cortelazzi C, Boccaletti V, Feliciani C, Di Nuzzo S. Psoriasis and seborrheic dermatitis in infancy and childhood. G Ital Dermatol Venereol. 2014;149(6):683-691.

55. Kumar P, Thomas J, Dineshkumar D. Histology of psoriatic erythroderma in infants: analytical study of eight cases. Indian J Dermatol. 2015;60(2):213.

56. Zhu KJ, He SM, Zhang C, Yang S, Zhang XJ. Relationship of the body mass index and childhood psoriasis in a Chinese Han population: a hospital-based study. J Dermatol. 2011;39(2):181-183.

57. Boccardi D, Menni S, La Vecchia C, et al. Overweight and childhood psoriasis. Br J Dermatol. 2009;161(2):484-486.

58. National Psoriasis Foundation. Psoriasis and Children Issue Brief. Available from: https://www.psoriasis.org/sites/default/files/advocacy/ PsoriasisandChildrenIssueBriefonepager.pdf. Accessed February 3, 2016.

59. Prabhu S, Shenoi SD. Quality of life issues in pediatric psoriasis. Indian J Paediatr Dermatol. 2012;13:17-20.

60. Kimball AB, Wu EQ, Guérin A, et al. Risks of developing psychiatric disorders in pediatric patients with psoriasis. $\mathrm{J} \mathrm{Am} \mathrm{Acad} \mathrm{Dermatol.}$ 2012;67(4):651-657.e1-e2.

61. Fluhr JW, Cavallotti C, Berardesca E. Emollients, moisturizers and keratolytic agents in psoriasis. Clin Dermatol. 2008;26(4): 380-386.

62. Smith CH, Jackson K, Chinn S, Angus K, Barker JN. A double blind, randomized, controlled clinical trial to assess the efficacy of a new coal tar preparation (Exorex $\left.{ }^{\circledR}\right)$ in the treatment of chronic, plaque type psoriasis. Clin Exp Dermatol. 2000;25(8):580-583.

63. Thami GP, Sarkar R. Coal tar: past, present and future. Clin Exp Dermatol. 2002;27(2):99-103.

64. Borska L, Andrys C, Krejsek J, et al. Genotoxic hazard and cellular stress in pediatric patients treated for psoriasis with the Goeckerman regimen. Pediatr Dermatol. 2009;26(1):23-27.

65. McGill A, Frank A, Emmett N, Turnbull DM, Birch-Machin MA, Reynolds NJ. The anti-psoriatic drug anthralin accumulates in keratinocyte mitochondria, dissipates mitochondrial membrane potential, and induces apoptosis through a pathway dependent on respiratory competent mitochondria. FASEB J. 2005;19(8):1012-1014.

66. Lebwohl M, Ali S. Treatment of psoriasis. Part 1. Topical therapy and phototherapy. J Am Acad Dermatol. 2001;45:487-498.

67. Zvulunov A, Anisfeld A, Metzker A. Efficacy of short-contact therapy with dithranol in childhood psoriasis. Int $J$ Dermatol. 1994;33(11):808-810.

68. Farber EM, Nall L. Childhood psoriasis. Cutis. 1999;64(5):309-314. 
69. Kiken DA, Silverberg NB. Atopic dermatitis in children, part 2: treatment options. Cutis. 2006;78(6):401-406.

70. Kimball AB, Gold MH, Zib B, Davis MW; Clobetasol Propionate Emulsion Formulation Foam Phase III Clinical Study Group. Clobetasol propionate emulsion formulation foam $0.05 \%$ : review of phase II open-label and phase III randomized controlled trials in steroidresponsive dermatoses in adults and adolescents. J Am Acad Dermatol. 2008;59(3):448-454.

71. Rim JH, Choe YB, Youn JI. Positive effect of using calcipotriol ointment with narrow-band ultraviolet B phototherapy in psoriatic patients. Photodermatol Photoimmunol Photomed. 2002;18(3):131-134.

72. Oranje AP, Marcoux D, Svensson A, et al. Topical calcipotriol in childhood psoriasis. J Am Acad Dermatol. 1997;36(2 Pt 1):203-208.

73. Liao YH, Chiu HC, Tseng YS, Tsai TF. Comparison of cutaneous tolerance and efficacy of calcitriol $3 \mu \mathrm{g} \mathrm{g}^{-1}$ ointment and tacrolimus $0.3 \mathrm{mg} \mathrm{g}^{-1}$ ointment in chronic plaque psoriasis involving facial or genitofemoral areas: a double-blind, randomized controlled trial. $\mathrm{Br} \mathrm{J}$ Dermatol. 2007;157(5):1005-1012.

74. Brune A, Miller DW, Lin P, Cotrim-Russi D, Paller AS. Tacrolimus ointment is effective for psoriasis on the face and intertriginous areas in pediatric patients. Pediatr Dermatol. 2007;24(1):76-80.

75. Mansouri P, Farshi S. Pimecrolimus 1 percent cream in the treatment of psoriasis in a child. Dermatol Online J. 2006;12(2):7.

76. Topical calcineurin inhibitors. Pediatric safety update: regulatory background. Poster presented at: FDA Pediatric Advisory Committee Meeting; May 16, 2011; Washington, DC. Available from: http://www. fda.gov/downloads/advisorycommittees/committeesmeetingmaterials/ pediatricadvisorycommittee/ucm255410.pdf. Accessed February 3, 2016.

77. Diluvio L, Campione E, Paternò EJ, Mordenti C, El Hachem M, Chimenti S. Childhood nail psoriasis: a useful treatment with tazarotene 0.05\%. Pediatr Dermatol. 2007;24(3):332-333.

78. Holme SA, Anstey AV. Phototherapy and PUVA photochemotherapy in children. Photodermatol Photoimmunol Photomed. 2004;20(2): 69-75.

79. Pasić A, Ceović R, Lipozencić J, et al. Phototherapy in pediatric patients. Pediatr Dermatol. 2003;20(1):71-77.

80. Ceović R, Pasić A, Lipozencić J, et al. Treatment of childhood psoriasis. Acta Dermatovenereol Croat. 2006;14(4):261-264.

81. Pang ML, Murase JE, Koo J. An updated review of acitretin a systemic retinoid for the treatment of psoriasis. Expert Opin Drug Metab Toxicol. 2008;4(7):953-964.

82. Cordoro KM. Topical therapy for the management of childhood psoriasis: part I. Skin Therapy Letter. 2008;13(3):1-3.

83. Kumar B, Dhar S, Handa S, Kaur I. Methotrexate in childhood psoriasis. Pediatr Dermatol. 1994;11(3):271-273.

84. Collin B, Vani A, Ogboli M, Moss C. Methotrexate treatment in 13 children with severe plaque psoriasis. Clin Exp Dermatol. 2009;34(3):295-298.

85. Kalb RE, Strober B, Weinstein G, Lebwohl M. Methotrexate and psoriasis: 2009 National Psoriasis Foundation Consensus Conference. J Am Acad Dermatol. 2009;60(5):824-837.
86. Perrett CM, Ilchyshyn A, Berth-Jones J. Cyclosporin in childhood psoriasis. J Dermatol Treat. 2003;14(2):113-118.

87. Alli N, Güngör E, Karakayali G, Lenk N, Artóz F. The use of cyclosporin in a child with generalized pustular psoriasis. $\mathrm{Br} J$ Dermatol. 1998;139(4):754-755.

88. Pereira TM, Vieira AP, Fernandes JC, Sousa-Basto AJ. Cyclosporin A treatment in severe childhood psoriasis. J Eur Acad Dermatol Venereol. 2006;20(6):651-656.

89. Paller AS, Siegfried EC, Langley RG, et al. Etanercept treatment for children and adolescents with plaque psoriasis. $N$ Engl J Med. 2008;358(3):241-251.

90. Trueb RM. Therapies for childhood psoriasis. Curr Probl Dermatol. 2009;38:137-159.

91. Kress DW. Etanercept therapy improves symptoms and allows tapering of other medications in children and adolescents with moderate to severe psoriasis. J Am Acad Dermatol. 2006;54(3 Suppl 2): S126-S128.

92. Pereira TM, Vieira AP, Fernandes JC, Antunes H, Basto AS. AntiTNF-alpha therapy in childhood pustular psoriasis. Dermatology. 2006;213(3):350-352.

93. Farnsworth NN, George SJ, Hsu S. Successful use of infliximab following a failed course of etanercept in a pediatric patient. Dermatol Online J. 2005;11:11.

94. Menter MA, Cush JM. Successful treatment of pediatric psoriasis with infliximab. Pediatr Dermatol. 2004;21(1):87-88.

95. Fotiadou C, Lazaridou E, Giannopoulou C, Ioannides D. Ustekinumab for the treatment of an adolescent patient with recalcitrant plaque psoriasis. Eur J Dermatol. 2011;21(1):117-118.

96. Pahlajani N, Katz BJ, Lozano AM, Murphy F, Gottlieb A. Comparison of the efficacy and safety of the $308 \mathrm{~nm}$ excimer laser for the treatment of localized psoriasis in adults and in children: a pilot study. Pediatr Dermatol. 2005;22(2):161-165.

97. Pacifico L, Renzi AM, Chiesa C. Acute guttate psoriasis after streptococcal scarlet fever. Pediatr Dermatol. 1993;10(4):388-389.

98. Grattan C, Burton JL, Manku M, Stewart C, Horrobin DF. Essential fatty-acid metabolites in plasma phospholipids in patients with ichthyosis vulgaris, acne vulgaris and psoriasis. Clin Exp Dermatol. 1990;15(3):174-176.

99. Lin YK, Yen HR, Wong WR, Yang SH, Pang JH. Successful treatment of pediatric psoriasis with Indigo naturalis composite ointment. Pediatr Dermatol. 2006;23(5):507-510.

100. Beattie PE, Lewis-Jones MS. A comparative study of impairment of quality of life in children with skin disease and children with other chronic diseases. Br J Dermatol. 2006;155(1):145-151.

101. de Jager ME, van de Kerkhof PC, de Jong EM, Seyger MM. A crosssectional study using the Children's Dermatology Life Quality Index (CDLQI) in childhood psoriasis: negative effect on quality of life and moderate correlation of CDLQI with severity scores. Br J Dermatol. 2010;163(5):1099-101.

102. Kurd SK, Troxel AB, Crits-Christop P, Gelfand JM. The risk of depression, anxiety and suicidality in patient with psoriasis: a populationbased cohort study. Arch Dermatol. 2010;146(8)(3):891-895.
Pediatric Health, Medicine and Therapeutics

\section{Publish your work in this journal}

Pediatric Health, Medicine and Therapeutics is an international, peerreviewed, open access journal publishing original research, reports, editorials, reviews and commentaries. All aspects of health maintenance, preventative measures and disease treatment interventions are addressed within the journal. Practitioners from all disciplines are invited to submit

\section{Dovepress}

their work as well as healthcare researchers and patient support groups. The manuscript management system is completely online and includes a very quick and fair peer-review system. Visit http://www.dovepress.com/ testimonials.php to read real quotes from published authors. 